\title{
Embelezamento, mídia e construção do corpo em narrativas de crianças Nuances de uma etnografia nos salões
}

\section{Vanessa Paula da Ponte ${ }^{1}$}

\author{
1 Universidade Estadual de Campinas - Unicamp, Campinas, Brasil. \\ Correo electrónico: nessaponte@gmail.com
}

Recibido:

15 de mayo de 2019 Aceptado:

o9 de octubre de 2019

doi: 10.34096/runa.v40i2.6263

\section{Resumo}

Este artigo nasce de uma pesquisa de doutorado cujo foco recai sobre a produção da imagem corporal de crianças na faixa etária entre 6 e 12 anos, pertencentes a diferentes realidades sociais e econômicas, frequentadoras de salões de beleza no Distrito Federal. Trata-se de uma etnografia, com abordagem antropológica da infância, a partir de uma perspectiva interseccional com marcadores sociais de diferença, tais como classe e raça. Apresentam-se dados que revelam a recorrência de crianças frequentadoras de salões assistindo a vídeos veiculados no YouTube protagonizados por outras crianças, as quais produzem o embelezamento de suas imagens corporais (maquiagem, cortes de cabelo, adornos). A partir da análise dos diálogos das crianças espectadoras desses vídeos, buscar-se-á refletir sobre como tais conteúdos audiovisuais reverberam nos processos de produção de suas autoimagens e subjetividades. $\mathrm{O}$ artigo convida a pensar como as crianças protagonistas e espectadoras dos vídeos estão, a todo instante, negociando com um mercado estético e cosmético a cada dia mais globalizado e sendo atravessadas por ele.

Embellecimiento, medios de comunicación y construcción del cuerpo en narrativas de niños. Matices de una etnografía en los salones

\section{Resumen}

Este artículo surge de una investigación de doctorado, cuyo objeto de estudio recae sobre la producción de la imagen corporal de niños y niñas en la edad comprendida de 6 a 12 años, pertenecientes a diferentes realidades sociales y económicas, frecuentadores de salones de belleza en el Distrito Federal. Se trata de una etnografía, con abordaje antropológico de la infancia, partiendo de una perspectiva de intersección con marcadores sociales de diferencia, tales como clase y raza. Se presentan datos que revelan la recurrencia de niños

Palabras clave

Belleza; Infancia; Medios de comunicación; Consumo; Etnografía 
y niñas que frecuentan los salones y ven videos difundidos por YouTube, protagonizados por otros niños y niñas que producen el embellecimiento de sus imágenes corporales (maquillaje, cortes de cabello, adornos). A partir del análisis de los diálogos de niños y niñas espectadores de esos vídeos, se buscará la reflexión sobre cómo tales contenidos audiovisuales repercuten en los procesos de producción de su autoimagen y subjetividad. El artículo invita a pensar en cómo los niños y niñas protagonistas y espectadores de los videos en cuestión, están en todo momento negociando y siendo influenciadas por un mercado estético y cosmético, cada día más globalizado.

\section{Embellishment, media and body construction in children's narratives. Nuances of an ethnography in the beauty salons}

\begin{abstract}
Key Words Beauty; Childhood; Media; Consumption; Ethnography
\end{abstract}

\section{Introdução}

\section{"Crianças desescrevem a língua. Arrombam as gramáticas" Manoel de Barros}

"Eu não consigo colocar meus pés fora de casa sem maquiagem", diz enfática Valentina, 7 anos, que define como as horas mais felizes do seu dia o momento em que os pais permitem que ela assista a vídeos tutoriais de maquiagem no YouTube. “Quero o meu cabelo assim, ó!”, demanda João, 9 anos, ao cabelereiro, mostrando uma foto do Felipe Neto, seu youtuber predileto. Lara, 11 anos, suspira ao afirmar: "Eu faria qualquer coisa pra ter uma penteadeira como a da Fernanda Lima (youtuber infantil, conhecida por suas dicas de beleza). Lucas, 4 anos, enquanto espera sua vez para cortar o cabelo, pede o tablet para sua mãe para assistir a alguns vídeos no YouTube. Ela responde, enfática: "Eu só libero se você largar essa chupeta." O menino, sem pestanejar, tira a chupeta, que é entregue à mãe, e pega, sedento, o tablet. Por sua vez, Lara, 9 anos, Amanda, 8 anos, e Bruna, 11 anos, regem uma brincadeira na área externa de um salão: brincam de youtuber. Cada uma desempenha um papel: Lara é a personal style que arruma a apresentadora detalhadamente; 
Amanda fica encarregada de filmar e, para isso, usa o celular da mãe; e Bruna apresenta o vídeo. Esta última diz, entusiasmada: "Dê seu like, compartilhe e se ligue nesse canal."

O registro dessas cenas e falas ocorreu no fluxo de uma pesquisa de doutorado cujo foco recai sobre a produção da imagem corporal de crianças na faixa etária entre 6 e 12 anos, frequentadoras de salões de beleza na cidade de Brasília e regiões administrativas. O estudo parte do princípio de que as crianças são agentes e intérpretes sutis de seus contextos culturais e prioriza as narrativas de meninas e meninos, pertencentes a diferentes realidades sociais e econômicas, acerca dos processos de construção de sua beleza. Trata-se de um trabalho etnográfico, com perspectiva socioantropológica da infância, fundamentado nos estudos de gênero, a partir de uma abordagem interseccional com outros marcadores sociais de diferença, tais como classe e raça. ${ }^{1}$

Busco, especialmente, compreender os modos pelos quais crianças vivenciam e significam a construção de suas aparências físicas, identificando o que isso revela sobre o meio social em que estão inseridas. No desenvolvimento da etnografia, procuro apontar a capilaridade da beleza no cotidiano das crianças, no sentido de destacar como ela se conecta com temas mais amplos da vida social, tais como consumo, saúde, sociabilidade, mídia, processos educativos e politização de corporeidades.

No presente artigo, movimento, mais especificamente, reflexões da pesquisa em curso que desvelam as relações entre beleza e mídia. Apresento dados que apontam que diversas crianças frequentadoras de salões assistem, recorrentemente, a vídeos veiculados no YouTube 2 protagonizados por outras crianças, as quais produzem o embelezamento de suas imagens corporais (maquiagem, adornos, cortes de cabelo). A partir da análise dos diálogos feitos com crianças com quem interajo no estudo, e que são espectadoras desses vídeos, pretendo refletir, especialmente, sobre como tais conteúdos audiovisuais reverberam nos processos de produção das autoimagens e percepções corporais dessas crianças.

Almejo organizar tais reflexões em torno de três tópicos. Primeiramente, apresentarei os procedimentos metodológicos e o campo de discussão sobre infância em que o trabalho etnográfico se situa. Em seguida, abrirei, ainda que minimamente, as portas dos salões pesquisados, apresentando como observei a presença dos referidos vídeos nos cotidianos das crianças que frequentam esses estabelecimentos. No último tópico, partilho uma possível interpretação sobre como os conteúdos audiovisuais pautados ressoam nos processos de produção das autoimagens das crianças.

Embora o escopo deste texto destaque, de forma pontual, as vivências de meninas e meninos com quem interajo em pesquisa e suas relações com vídeos veiculados no YouTube, muitos dos quais gravitam em torno do tema da bele$\mathrm{za}$, ressalto que o número de crianças brasileiras de diferentes classes sociais que acessam a referida rede de compartilhamento é expressivo. Uma pesquisa de grande porte intitulada "Geração YouTube: um mapeamento sobre o consumo e a produção infantil de vídeos para crianças de zero a 12 anos no Brasil", realizada pela ESPM Media Lab entre 2015 e 2016, aponta que a audiência de canais de youtubers mirins cresceu quase 6 vezes em um ano no Brasil, e o número de visualizações dos canais feitos por crianças na plataforma teve um aumento de $564 \%$. Outro dado foi o aumento do número de inscritos nesses canais: 550\%.3 Além de mostrar a forte incidência de vídeos para o público
1. Gênero e raça são termos utilizados aqui sem conotações essencialistas. Os trabalhos de Brah (2006), Butler (2001) e Fanon (2008) têm sido inspiradores para pensá-los de forma socialmente situada.
2. YouTube é um site de compartilhamento de vídeos enviados pelos usuários através da internet.
3. Disponível em: http://pesquisasmedialab.espm.br/criancas-e-tecnologial. Acesso em: 6 jul. 2017. 
4. Disponível em: http://sites. correioweb.com.br/app/noticia/ encontro/revista/2012/12/o5/interna_revista,161/os-reis-do-salao. shtml. Acesso em: 1 maio 2017.

5. Disponível em: http://www. fecomercio.com.br/noticia/ brasileiros-gastam-mais-de-r20-bilhoes-por-ano-em-saloesde-beleza-1. Acesso em: set. 2017. infantil e realizados por crianças, o estudo mostra como há neles o estímulo ao consumo e como o universo do embelezamento está presente como um dos temas centrais.

Desse modo, a discussão aqui movimentada tenciona, a partir desse universo mais circunscrito à pesquisa, contribuir para uma reflexão mais ampla sobre as relações entre infância, produção de corporeidades, mídia e consumo. Com esse intento, inicio convidando a uma aproximação ao contexto do estudo, a sua metodologia e ao campo de discussão em que a pesquisa é tecida.

\section{O contexto da pesquisa nos salões, seus fios metodológicos e teóricos}

A presença de salões de beleza nas diferentes regiões de Brasília é intensa. Conforme reportagem do jornal Correio Braziliense, intitulada "Reis do salão", "a chance de um brasiliense cruzar com um salão ou instituto de beleza em seu caminho é quase 10 vezes maior do que de se deparar com uma padaria ou 12 vezes mais no caso de uma farmácia, segundo dados do Serviço Brasileiro de Apoio às Micro e Pequenas Empresas (Sebrae)." ${ }^{4}$ Conforme o levantamento do Sindicato dos Salões, Barbeiros, Cabeleireiros e Institutos de Beleza (Sincaab$\mathrm{DF})$, em meio às quadras comerciais, nas proximidades das mansões à beira do Lago Paranoá e no torvelinho de ruas que se desenham distantes do Eixo Monumental, há mais de 7 mil comércios do segmento. No que tange à empregabilidade, são 13,8 mil profissionais atuantes nesse setor na capital do país. A média é de 20 salões ou barbearias abertos mensalmente em Brasília.

Embora a pesquisa tenha como foco a capital, vale destacar que o crescimento vertiginoso dos salões de beleza não é exclusivo dessas paragens. Hoje há em torno de 342 mil salões formalmente registrados no Brasil. Conforme o Sebrae (2013, pp. 17): "Cerca de 7 mil salões de beleza são abertos por mês em todo o território nacional, a maioria como microempreendedores individuais." Considerando o alto grau de informalidade dessas atividades, "estes números trazidos à realidade fática de mercado, ou seja, negócios informais somados aos formais, seguramente ultrapassam a casa de 1 milhão" (Sebrae, pp. 17, 2013).

Em 2015, a Federação do Comércio de Bens, Serviços e Turismo do Estado de São Paulo (FECOMÉRCIO) divulgou, em sua página virtual ${ }^{5}$, informações advindas da Pesquisa de Orçamentos Familiares (POF), realizada pelo IBGE, que revelam que as famílias brasileiras investem, anualmente, $R \$ 20,3$ bilhões em serviços de cabeleireiro, manicura e pedicura. A reportagem aponta que o investimento em cursos regulares de educação (da pré-escola ao ensino médio) consiste em $\mathrm{R} \$ 19,86$ bilhões - ou seja, as famílias brasileiras gastam mais com salões de beleza do que com educação. O investimento nos serviços estéticos também supera os $R \$ 19,86$ bilhões referentes ao volume anual gasto com alimentos básicos, tais como aves e ovos. A reportagem destaca ainda que "No comparativo por renda, após a classe $C$, a A é a que mais investe nestes serviços, com o montante de mais de $\mathrm{R} \$ 3$ bilhões, seguida da $\mathrm{B}$, com cerca de $\mathrm{R} \$ 2,9$ bilhões, enquanto os consumidores da classe $\mathrm{D}$ despendem de $\mathrm{R} \$ 1,4$ bilhão e da E, R\$1,1 bilhão."

Esses dados se devem ao fato de que entre as sociedades contemporâneas, a brasileira é uma das que mais movimenta a ideia de transformar e modelar o corpo. Nas mais diversas regiões e contextos do país, propaga-se a noção de que o corpo deve ser exposto, experimentado, vivido. Diariamente, pessoas das 
mais diferentes idades e condições econômicas são estimuladas a administrar a própria aparência, a redesenhar as formas físicas. Esse cenário incrementa não apenas o crescimento dos salões, mas de outros espaços que gravitam em torno dos cuidados com a estética corporal, como as academias de musculação. De acordo com o SEBRAE ${ }^{6}$, o Brasil ocupa o segundo lugar mundial em quantidade de academias, perdendo apenas para os Estados Unidos.

Nesse sentido, é pertinente também trazer à baila a pesquisa fomentada pela Sociedade Internacional de Cirurgia Plástica (SICP), envolvendo países de todo o mundo, que aponta o Brasil em $2^{\underline{o}}$ lugar no ranking relacionado à realização de cirurgias estéticas. ${ }^{7}$ No tocante ao público infantil, o país destaca-se em segundo lugar no ranking do mercado mundial de cosméticos e serviços estéticos, abaixo dos Estados Unidos e acima da China. A densa circularidade de crianças de diferentes realidades sociais nos salões de beleza, lócus deste estudo, sem dúvidas alavanca parte significativa desse mercado.

Pude testemunhar isso nos trânsitos da pesquisa, nos quais visitei em média 35 estabelecimentos situados no Plano Piloto e nas Regiões Administrativas de Brasília. Alguns são focados exclusivamente no público infantil; outros atendem a um público mais variado, que engloba tanto adultos quanto crianças. Nessas andanças, frequentei salões de beleza minuciosamente montados por arquitetos e decoradores, com equipamentos sofisticados, significativo estoque de produtos de beleza (incluindo importados) e com equipes administrativas de limpeza e especializadas em serviços estéticos. Da mesma forma, realizei pesquisa em salões situados em regiões com dificuldades de infraestrutura, localizados em ruas que sequer foram asfaltadas. Estabelecimentos bem mais modestos no que diz respeito a instalações físicas, quantidade de estoque, número de trabalhadores e cartela de preços. Embora as diferenças saltem aos olhos, os serviços oferecidos para crianças possuem relativa semelhança: cortes de cabelo, alisamento, penteados, unhas decoradas, vendas de adornos, colorações e cosméticos. Neste artigo, coloco em pauta cenas e análises pertinentes a três deles, localizados na Asa Norte, na Asa Sul e na Ceilândia.

Ao estudar a produção do embelezamento entre crianças nesses espaços, pretendo estar em consonância com as premissas apontadas por Muller e Hassen (2009, pp. 473) relacionadas aos estudos da infância: “1) reconhecimento da infância como categoria social; 2) necessidade de pesquisa com as crianças e não somente sobre elas; 3 ) crítica às teorias tradicionais da socialização; 4) novas teorizações sobre a infância; 5) crítica à marginalização das crianças". Tais premissas foram levantadas pelas autoras a partir de um estudo amplo e detalhado de trabalhos produzidos desde o final dos anos 80 , que tematizam a infância em diversos campos do conhecimento, em especial nas ciências sociais. Outro ponto marcante desses estudos da infância por elas mencionados, e que converge com o trabalho aqui em pauta, é o fato de haver um incentivo, cada vez mais intenso, a pesquisas nos mais diferentes contextos vivenciados pelas crianças, não apenas no escolar.

Nesse horizonte, cabe destacar as ideias de Sirota (2001). A autora afirma que, antes dos anos 90, nos estudos sociológicos com atores infantis, imperava uma visão funcionalista durkheimiana que considerava as crianças seres fundamentalmente imaturos, incompletos e inteiramente passivos no processo de socialização, designados a absorver o que estava posto socialmente. Nesse tipo de abordagem, o foco da análise volta-se para os dispositivos institucionais, tais como a escola, a família e a justiça. Adultos - por meio de observações distanciadas - deslindavam em relatórios sobretudo "os problemas colocados
6. Disponível em: https://m. sebrae.com.br/Sebrae/ Portal\%20Sebrae/UFs/RJ/ Anexos/Relat\%C3\%B3rio\%20 SIS\%20Fitness\%20-\%20 Precifica\% $3 \% \mathrm{C}_{3} \mathrm{~A}_{7} \mathrm{C}_{3} \% \mathrm{~A}_{3} \mathrm{O}$ pdf. Acesso em: 24 fev. 2017.

7. Disponível em: http://www.ebc. com.br/noticias/saude/2013/o4/ ascensao-da-classe-c-contribuiupara-o-aumento-de-cirurgias-plasticas-no. Acesso em: 4 fev. 2017. 
pela escolarização, seja em termos de políticas públicas, ou de modos de frequência" (Sirota, 2011, pp. 26-27). Meninas e meninos eram vistos, muitas vezes, somente como alunos e "concebidos apenas como receptáculos mais ou menos dóceis de uma ação de socialização no interior de uma instituição com objetivos claros para o sociólogo" (Sirota, 2011, pp. 16).

Conforme salienta a autora, a sociologia da infância, emergente nos anos 90, veio contrapor-se à perspectiva funcionalista, contribuindo com outros modos de olhar as crianças, percebendo suas participações ativas nos processos de socialização. Dessa feita, passou "a inverter a proposição clássica, não de discutir sobre o que produzem a escola, a família ou o Estado, mas de indagar sobre o que a criança cria na intersecção de suas instâncias de socialização" (Sirota, 2011, pp. 19).

No âmbito da sociologia da infância, as crianças passaram a ser vistas de forma diferenciada, não mais simplesmente como alunos. Além da escola, elas passaram a ser observadas nos mais diferentes espaços sociais nos quais interagem. Sobre isso, são pertinentes as palavras de Delgado e Müller (2005, pp. 175-176):

Estamos acostumados a pensar nas crianças como alunas e alunos, geralmente em escolas ou espaços educativos formais, ou ainda nas crianças dentro de creches e pré-escolas. Estamos condicionados a pensar em educação como algo institucionalizado e vivido em espaços escolares. Na verdade, temos pesquisado e produzido muito pouco sobre outros espaços educativos como a televisão, os videogames, as salas da internet, os movimentos sociais, as ruas, as vilas e favelas com seus espaços informais e clandestinos de educação, as academias, os shoppings, as escolas de samba ou as danceterias. Enfim, pouco nos interessamos pelas crianças e suas culturas, interagindo em espaços que nós adultos ainda desconhecemos, ou pelos quais temos passado sem refletir de forma mais prolongada.

Em plena sintonia com o que afirmam as autoras, penso que os salões configuram um desses espaços com caráter pedagógico e, ao mesmo tempo, de entretenimento, que são indiscutivelmente visitados por um número expressivo de crianças de diferentes realidades sociais, e que merecem ser notabilizados nos âmbitos dos estudos da infância. Nos cotidianos dos salões, tenho acesso às narrativas e histórias de vários momentos da vida de meninos e meninas, seja sobre a escola, os aconchegos dos seus lares ou outros espaços de sociabilidade. Nos salões, contam-se histórias pessoais recorrentemente. Ali vislumbro detalhes do modo como as crianças apreciam se vestir, se adornar; apreendendo nuances que vão além das fardas e uniformes do colégio. É possível captar singularidades nesses detalhes. Observo os objetos que carregam consigo nas visitas feitas aos estabelecimentos: brinquedos, eletrônicos, bolsas etc. Posso vê-los diante dos espelhos, apreciando suas imagens, em meio aos serviços estéticos, adquirindo e consumindo produtos que prometem embelezar suas aparências físicas. Vejo as negociações entre crianças, responsáveis e funcionários em torno da transformação da imagem corporal, as fotos que tiram ao terminar os serviços, as poses, as resistências. São muitos os detalhes que a própria atmosfera desses espaços oferece, ampliando as possibilidades para um estudo com crianças, compreendendo suas narrativas e agências.

Para captar e analisar essas sutilezas, realizo nos salões uma observação participante, na qual estabeleço uma relação dialógica com as crianças. Escolho o fazer etnográfico como cerne da pesquisa ora proposta. Fazer que consiste, com base em Peirano (2014), na produção de uma forma de conhecimento em que teoria e empiria se articulam. É nesse movimento que a etnografia se tece, 
possibilitando à pesquisadora conhecer profundamente não só as vivências dos sujeitos participantes de seus trabalhos, mas o contexto social em que eles estão inseridos. Nesse sentido, ao movimentar o trabalho etnográfico, busco descrever, interpretar e analisar o mundo de significados e símbolos construído pelas crianças em relação à produção de suas belezas. Como orienta Geertz (1989), a partir da teoria hermenêutica da cultura, o fundamental é procurar compreender o que as crianças pensam sobre o que fazem.

Concordo ainda com a ideia de Corsaro (2011), para quem a etnografia é adequada especialmente para estudos com crianças, uma vez que é capaz de demonstrar como elas "constroem sentido e contribuem para processos de reprodução e mudanças sociais" (Corsaro, 2011, pp.61). O olhar etnográfico permite, portanto, o foco nas singularidades e subjetividades de meninas e meninos, compreendendo-se o fato de que essa esfera tão íntima e individual está em diálogo constante com a dimensão social.

Com esse fim, observo as crianças e com elas interajo nos salões, seja no momento em que aguardam para serem atendidas, durante a realização do atendimento, ou até mesmo depois dos serviços realizados. Utilizo os recursos das conversas informais seguindo a trilha de Sousa (2017, pp. 50), que afirma que tais conversas "viram aliadas do pesquisador que investiga a infância, por poderem se desenrolar enquanto se brinca, se trabalha ou se aprende com as crianças, em qualquer ambiente sem formalismos." Esse tipo de interação ocorre com duas condições: a disposição e o desejo das crianças para a interação e a autorização dos familiares. Entrevistas com as equipes dos salões e com os responsáveis pelas crianças também são realizadas, pois julgo elucidativo acessar as redes de relações. Desenvolvo formas colaborativas de construção do conhecimento e busco interagir de forma descontraída com as crianças. Participo de suas brincadeiras, aprecio seus desenhos, escuto o que dizem sobre os filmes e os vídeos a que assistem durante o atendimento.

Também inspiro-me em pesquisas de fôlego que se debruçaram sobre os salões de beleza. Dentre elas, destaco os trabalhos de Gomes (2002), Bouzón (2010) e Arango (2016). Bouzón (2010, pp. 14) assinala que esses salões constituem "um dos mais ricos espaços dedicados à preparação coletiva e ritualística do 'corpo belo"'. Para a autora, tais estabelecimentos movimentam entre os profissionais e o seu público "um senso do que é esteticamente 'apropriado' ou 'inapropriado', em relação a categorias de gênero, idade, classe e cor de pele" (Bouzón, 2010, pp. 293). Arango (2016), da mesma forma, vislumbra os salões como espaços de reprodução ou de negociação das normas de beleza e prestígio, atravessados pelos marcadores sociais da diferença. Gomes, por sua vez, chama a atenção para os salões como "espaços culturais, corpóreos, estéticos e identitários e que, por isso, nos ajudam a refletir um pouco mais sobre a complexidade, as ambiguidades e os conflitos em torno da identidade negra." (2002, pp. 1)

Para os propósitos deste texto, além de movimentar procedimentos e leituras próprios da etnografia e da observação participante, recorro a trabalhos que oferecem um suporte para compreender as interações e experiências das crianças com a internet. Nesse sentido, ancoro-me no trabalho de Girardello (2008), que destaca "a explosão do mundo digital" e sua forte incidência nas vidas de meninos e meninas de diferentes segmentos sociais. Na pesquisa realizada pela autora com 2.000 crianças que cursavam a primeira série do ensino fundamental em Florianópolis, "o computador foi apontado por 100\% das crianças entrevistadas na favela mais empobrecida da cidade como mídia 
favorita, mesmo por aquelas que nunca tocaram o teclado de um computador" (Girardello, 2008, pp. 1). A autora enfatiza a importância de atentar para a produção cultural das crianças nos contextos das novas mídias, compreendendo o que torna esses contextos tão apaixonantes para meninos e meninas, e afirma que a educação que não pensa a mídia é uma educação incompleta.

Neste exercício de reflexão, também terei em mente as ideias de Dornelles (2005), especialmente quando reflete sobre a cyberinfância, termo que indica o atravessamento das "novas tecnologias nos cotidianos das crianças", ou seja, que alude à infância online, completamente conectada a internet, games, celulares, computadores, tablets. Conforme a autora, por meio do uso dessas possibilidades virtuais interativas, as crianças encontram novas formas de se sociabilizarem e de se produzirem como sujeitos infantis. Elaborado esse diálogo inicial, no qual apresentei alguns fios teóricos e metodológicos, narro, a seguir, cenas que mostram as vivências de crianças com vídeos.

\section{Crianças, salões e telas: conexões em torno do embelezamento}

As telas permeiam, com força, o dia a dia nos salões. No fazer da pesquisa, chamaram a minha atenção as cenas corriqueiras das pequenas mãos com toques habilidosos nas telas de tablets, celulares, controles remotos de vídeos games etc. Crianças que nem completaram um ano já deslizam os dedinhos nas telas dos celulares touch screen. Em salões de classe média situados na Asa Norte e na Asa Sul, há telas em frente à maioria das cadeiras de corte, nas quais são ligados DVDs ou jogos de videogame, acionados durante o atendimento. Mesmo nos salões com baixos recursos aquisitivos, há pelo menos um aparelho de tevê ligado constantemente. Nos salões situados na Ceilândia, onde o poder aquisitivo é baixo, podem-se acompanhar crianças pedindo os celulares de seus pais para brincar e assistir a vídeos no YouTube e em outros sites. Por meio desses toques, desse manuseio, elas acessam desenhos animados, filmes, jogos, vídeos, redes sociais, e têm contato com seus super-heróis, as princesas da Disney, a Barbie, ou com seus artistas e atletas preferidos. Muitos desses personagens representam os referenciais de corpo belo dessas crianças. Algumas, inclusive, tiram selfies que são publicados nas redes sociais dos próprios salões, mostrando como ficaram parecidas com os personagens ou youtubers de que gostam.

Durante as observações num salão de classe média da Asa Norte, Marina, 7 anos, estudante de escola particular, que assistia a um vídeo em seu tablet, chamou-me a atenção. Com a permissão da menina, aproximei-me e vimos juntas, no YouTube, Fernanda Lima, uma garota de 10 anos, dona do canal "Bonecas em ação", protagonizando o vídeo intitulado "Um tour pela minha penteadeira." Fernanda mostrava, em detalhes, as suas maquiagens, perfumes, cosméticos, adornos e indicava o local para a compra de uma penteadeira

8. O vídeo pode ser acessado em: https://youtu.be/LL708tHDikl. Até o momento, ele conta com mais de 150 mil visualizações.

9. Termo designado para pessoas que produzem e enviam vídeos para o YouTube e que alcançam uma difusão significativa destes, com expressivo número de assinantes nos canais. São considerados influenciadores digitais. semelhante à sua. Notei a grande quantidade de produtos de embelezamento apresentados, a propaganda que a menina fazia da loja e o número de visualizações do vídeo. ${ }^{8}$ Perguntei a Marina se ela costumava assistir a vídeos parecidos, com que frequência e por que se interessava por eles. De forma entusiasmada, a garota respondeu: "Eu adoro! Assisto sempre. Tem canais que eu amo de paixão." A menina começou a me mostrar canais semelhantes. Depois, visitei o mesmo canal e assisti a outros vídeos protagonizados pela jovem youtuber ${ }^{9}$ Fernanda fazendo alusão à beleza, como, por exemplo, "Como cuidar das minhas unhas" e "Cortando meu cabelo" (este último mostra um dia da menina no salão). 
A cena descrita abriu uma porta para as reflexões aqui movimentadas. A partir daquele momento, permaneci atenta às crianças que portavam aparelhos eletrônicos, aos vídeos acessados e às suas impressões sobre os mesmos. Vale mencionar que muitos dos meninos e meninas pertencentes a famílias com alto poder aquisitivo possuem seus próprios tablets, smartphones e computadores. Por sua vez, as crianças de famílias com recursos financeiros mais escassos não ficam alheias a essas tecnologias. Utilizam celulares de familiares, os computadores da escola e de lan houses (cybercafés). Foi Elisa, 9 anos, estudante de escola pública, frequentadora de um salão de pequeno porte na Ceilândia, no setor habitacional Sol Nascente, região carente de infraestrutura e saneamento básico, que me mostrou o canal de outra youtuber mirim, Julia Silva. Nele, há uma seção chamada maquiagens e looks. Entre os vídeos, consta o "Arrume-se comigo, 3 looks". ${ }^{10}$ A menina dá dicas de como se arrumar para ir passear, ir a festas com as amigas e ao cinema. Durante o vídeo, Júlia faz propaganda da loja em que é possível comprar as roupas, sapatos e acessórios. Elisa fala com encanto sobre a protagonista do canal: "Ela é show! Linda. Muita roupa, maquiagem, tudo caro." Seguir as dicas de Julia é uma missão nada simples para as condições financeiras da menina e de sua mãe, vendedora ambulante. Afinal, o pelejado orçamento era, como dizia esta, "apertado demais para essas coisas."

Acessei durante 4 meses, com regularidade, o YouTube. Nesse exercício, deparei-me com uma infinidade de vídeos de crianças consideradas youtubers, inclusive algumas com tenra idade, como Julie, de 4 anos, que apresenta um tutorial de maquiagem para o parquinho e para o shopping. ${ }^{11} \mathrm{O}$ canal de Julie alcançou um número tão expressivo de visualizações que a menina acabou aparecendo em jornais e programas de televisão. Vale mencionar que a plataforma também conta com vídeos sobre beleza encenados por crianças que não são necessariamente youtubers, ou seja, que não possuem um canal com visualizações expressivas. Já os vídeos protagonizados por meninos tematizam brincadeiras, games, viagens e peripécias. Um bom exemplo disso é o canal Nick e Nelson, encenado por Nelson Victor, 14 anos, e seu irmão caçula, Nicolas, $5 .{ }^{12}$ Uma exceção foi o canal de Jake Warden de Denver ${ }^{13}$, residente do Colorado, que traz tutoriais de maquiagem com um grande número de visualizações.

Verifiquei que os dados por mim levantados durante o tempo de pesquisa no YouTube estavam em sintonia com uma pesquisa de grande porte intitulada TIC Kids Online Brasil. ${ }^{14}$ Gerasimczuke e Karageorgiadis (2017, pp. 40) apontam que, apesar de o YouTube ser um site destinado a indivíduos maiores de 18 anos, crianças circulam pela plataforma: "Assim, como ocorre em outras redes sociais, elas criam seu próprio canal e passam a alimentá-lo diariamente com produções audiovisuais nas quais são as protagonistas." Conforme os autores, nasce uma geração de produtores de conteúdo para o YouTube - os youtubers mirins. Com o tempo, seus canais passam a ser vistos e acompanhados por um número cada vez maior de crianças. "Em 2016, dos 230 canais analisados pelo mapeamento, os 110 infantis somavam quase 50 bilhões de visualizações, contra pouco mais de 2 bilhões dos 120 canais restantes." (pp. 40).

Diante das cenas observadas nos salões, do estudo das imagens vislumbradas nos vídeos e com o suporte da literatura pesquisada, trago algumas questões norteadoras para a reflexão. De que forma as categorias corpo e beleza são operacionalizadas cotidianamente em tais estabelecimentos e nesses vídeos? Como as crianças manejam tais categorias? Dialogando com elas, subvertendoas, tensionando-as? Como isso reverbera nos processos de produção de suas
10. O vídeo pode ser acessado em: https://youtu.be/G5bVgdiBuVg.

11. O vídeo pode ser acessado em: https://youtu.be/UFFBv308ZaQ.

12. O canal pode ser acessado em: https://youtu.be/D9_uS16h5wl.

13. O vídeo pode ser acessado em: https://youtu.be/1Tc|1515 $\mathrm{P}_{3}$ w.

14. Disponível em: https://www. cgi.br/publicacao/pesquisasobre-o-uso-da-internet-porcriancas-e-adolescentes-no-brasiltic-kids-online-brasil-2016/. 
autoimagens corporais? O que isso revela sobre os contextos sociais em que essas crianças estão inseridas? Na próxima seção, procuro lançar luz a essas questões.

\section{Entre salões, espelhos e vídeos: estímulos à beleza no cotidia- no das crianças}

A pesquisa vem apontando que o conteúdo audiovisual encenado pelas crianças nos vídeos aqui pautados apresenta a predominância de determinado padrão estético, que valoriza um corpo magro, cabelos lisos, algo semelhante ao que ocorre no interior dos salões. Há uma similaridade entre as cenas dos vídeos e as cenas observadas nos referidos estabelecimentos, que consiste na diferença dicotômica de gênero nas formas de pensar as performances corporais de meninos e meninas. Geralmente, as meninas trazem em seus discursos uma forte centralidade do corpo belo, maquiado em sintonia com a moda, o "corpo da princesa". Já a beleza dos meninos vem apresentada a partir da figura do herói, das brincadeiras de ação. Esses estímulos e investimentos para a produção cotidiana de princesas e heróis revitalizam a reposição e a persistência de um padrão heteronormativo, mesmo em face às propaladas transformações sociais concernentes às representações de gênero.

Os efeitos desses discursos reiterativos de normas regulatórias ressoam na produção de corporeidades, na produção das subjetividades e influenciam nas representações das diversas crianças sobre si e sobre outros. Penso que é preciso compreender quais outras formas ficam abafadas, silenciadas, invisibilizadas no reforço tão contínuo de marcar tais papéis e comportamentos. Além disso, é importante questionar criticamente em que medida esse silenciamento pode produzir assimetrias e desigualdades. Não se trata de colocar em cheque as figuras de heróis e princesas, mas de buscar compreender que outras possibilidades estão sendo abafadas quando crianças não se encaixam, deslocam, negam tudo isso. O vídeo do garoto Jake e seu tutorial de maquiagem quebra esse esquema marcadamente binário e acaba recebendo um arsenal de comentários pejorativos. As naturalizações que reduzem modelos de feminilidade e masculinidade tencionam restringir significativamente as possibilidades de ser e estar no mundo.

Outro ponto que ficou evidente no exercício da pesquisa, tanto na análise das cenas no interior dos salões como na análise dos vídeos, é o entendimento da imagem corporal como um elemento central na definição de quem deve ou não ser admirado. A beleza é vista como uma forma de alcançar a aceitação social plena. Entendimento estimulado por diversas instâncias sociais: indústrias de cosméticos, medicina estética, mercado da beleza, mídia e tantas outras que incitam o empreendimento de um trabalho sistemático na aparência física. Venho refletindo que essa valorização da beleza gera, por meio de suas nuances, uma acentuada distinção de classe, gênero e raça, evidenciando mecanismos de reprodução de desigualdades.

Nessa trilha de reflexão, aludo a trabalhos como o de Finco e Oliveira (2011). No texto intitulado "Sociologia da pequena infância e a diversidade de gênero e raça nas instituições de educação infantil", as autoras se engajaram em compreender "as relações sociais e as práticas educativas ocorridas nas creches na pré-escola com o objetivo de verificar as maneiras pelas quais tais relações produziam e revelavam a questão racial e a questão de gênero" (Finco; Oliveira, 2011, pp. 17). Elas observaram que havia diferenciações nas relações afetivas 
construídas entre as professoras e as crianças. As práticas de elogiar a aparência física, dar colo, afagar o rosto, os cabelos, não eram dispensadas a todas as crianças de forma simétrica. Ao contrário, ocorriam de maneira diferenciada para meninas e meninos, crianças brancas e crianças negras. Finco e Oliveira acionam o conceito de paparicação, que consiste justamente nesses gestos de valorização conferidos a meninas e meninos.

Nesse sentido, analisou-se que as crianças brancas eram muito mais paparicadas do que as negras, acarretando uma clara discriminação. "Os atributos físicos considerados bonitos eram sempre associados às crianças brancas: as meninas preferidas pelas professoras eram caracterizadas princesas ou filhas" (Finco; Oliveira, 2011, pp. 66). As autoras nos fazem pensar os desdobramentos dessa assimetria de tratamento para a forma como as crianças estabelecem relações com seus próprios corpos, gêneros, raças.

Ao analisar os vídeos e o movimento nos salões, também observo a diferença marcante de paparicos para crianças que possuem determinados atributos físicos. Aquelas que possuem cabelos lisos, pele branca, olhos claros e que são magras recebem sempre mais elogios. Na maioria dos salões, as meninas de cabelo crespo são estimuladas a prender suas madeixas, diminuir o volume no corte ou mesmo a alisá-las. As de cabelos lisos, ao contrário, são orientadas a exibi-los. É certo que há salões que procuram construir um novo olhar. Ensinam a amar o cabelo crespo, elogiá-lo, tocá-lo com carinho, empoderá-lo. Todavia, nesses locais não observei o mesmo grau de elogios para crianças magras e gordas, por exemplo. Até mesmo a estética das meninas negras é muito mais evidenciada do que a dos meninos. Não vi imagens representativas deles nas paredes dos salões, por exemplo. O mesmo ocorre entre youtubers mirins: as de maior popularidade são crianças brancas e de cabelos lisos, como a Julia Silva, mencionada por uma das minhas interlocutoras.

Nesta pesquisa, fico atenta ao modo como esses incentivos diários dados pelos elogios e reforços positivos podem ressoar não só na composição da aparência física, mas na forma como as crianças se relacionam consigo mesmas, com os outros e com os contextos sociais. Penso nos prejuízos que a ausência desses incentivos acarreta na saúde física e emocional de meninas e meninos. Vale mencionar a youtuber mirim Ana Barbosa, de 11 anos, menina negra, que em seu canal dá dicas de penteado, maquiagem e cuidados com o cabelo. ${ }^{15}$ Ana ganhou notoriedade porque sofreu uma enxurrada de ataques racistas, desqualificando sua aparência física e seus cabelos, classificados por espectadores como "ruim". ${ }^{16}$ Refletindo sobre isso, aludo a Gomes (2002, pp. 20-21), quando afirma que "o cabelo do negro, visto como 'ruim' é expressão do racismo e da desigualdade racial que recai sobre esse sujeito."

Algo que também se torna evidente diante do número estrondoso de youtubers mirins e da forte presença desses vídeos nas vidas de meninos e meninas de diferentes classes sociais é a necessidade de refletirmos sobre a publicidade infantil. Como podemos notar nos vídeos elencados, muitas das crianças que os protagonizam acabam se tornando "promotoras de venda", estimulando de forma lúdica hábitos de consumo. Desse modo, é importante atentar para as relações comerciais que podem existir a partir da produção e recepção de tais vídeos. Tanto as crianças que encenam os vídeos como aquelas que os apreciam estão submetidas a toda sorte de produtos. Nesse caso, como aponta Dornelles (2005, pp. 94), "não se consome apenas o objeto em si, mas tudo aquilo que ele possa representar para meninos e meninas, status, conforto, desejos e beleza, saber, poder." É fundamental pensar como os corpos das
15. O canal pode ser acessado em: https://www.youtube.com/ watch?v=RoDUforzReQ.

16. Disponível em: https:// noticias.r7.com/cidades/youtuberde-11-anos-e-hostilizada-comcomentarios-racistas-17052018. 
17. Ver: http://alana.org.br/.

18. A Constituição Federal, através do Estatuto da Criança e do Adolescente (ECA), do Código de Defesa do Consumidor e por meio de uma resolução de 2014 do Conselho Nacional dos Direitos da Criança e do Adolescente (Conanda), prima pela proteção da criança diante da publicidade infantil. A ausência aqui questionada é de uma lei específica que amplie o diálogo sobre o consumo e promova a sua eficácia. crianças que protagonizam os vídeos e das que são espectadoras, estão, a todo instante, sendo atravessados por um mercado estético e cosmético a cada dia mais globalizado, com o qual negociam.

Acredito na importância de compreender as percepções e agências dessas crianças em relação ao consumo. Isso nos impele a buscar um entendimento de como ritualizam, organizam e classificam as experiências de consumo. De que forma isso reverbera na produção de diferentes subjetividades e sociabilidades e de que maneira ecoa nas relações que estabelecem com suas próprias imagens. É preciso, inclusive, pensar nas condições desiguais de consumo. Como provoca o estudo de Edmonds (2002, pp. 255): “Se o consumo de produtos e serviços de beleza torna-se essencial para manter uma aparência considerada 'normal', aqueles que não podem consumi-los suficientemente se tornam cada vez mais marginais."

É importante frisar, tal como critica o Instituto Alana, ${ }^{17}$ que há uma ausência de regulamentação para publicidade infantil no YouTube. A organização aponta os efeitos danosos da publicidade direcionada às crianças, uma que vez que veicula serviços e produtos que aguçam a vaidade infantil, propagando, assim, a exigência de um tipo físico que não contempla, nem de longe, os corpos sociais que são física e subjetivamente diversos. Outros tantos estudos também alertam para como os discursos produzidos pela mídia ou pela moda produzem efeitos sobre os corpos e as mentes das crianças (Sampaio, 2000; Hamann, 2002). ${ }^{18}$

Buckingham (2012) propõe compreender como essas programações voltadas ao público infantil falam com as crianças, como as convidam a se envolverem com o conteúdo transmitido. $\mathrm{O}$ autor defende a necessidade de se entender quais as funções das crianças como atores ou participantes dentro dos programas, e o modo como as relações adulto/criança são representadas. Podemos voltar o olhar também para a programação adulta, pois muitas crianças acabam por assistir a conteúdos desse tipo (como os tutoriais de maquiagem produzidos por adultos, por exemplo), sejam acompanhadas dos seus responsáveis ou até mesmo sozinhas. Assim, "é interessante observar as versões ou aspectos da vida adulta que elas escolhem para seguir e aqueles que elas rejeitam ou aos quais resistem" (Buckingham, 2012, pp. 112).

A perspectiva de Buckingham é interessante porque, ao invés de compreender o significado como algo que a mídia meramente distribui a públicos passivos, defende o estudo das "diversas maneiras nas quais os significados e prazeres são construídos, definidos e difundidos" (pp. 114). Neste exercício, é preciso levar em consideração que as crianças não devem ser abordadas de maneira essencialista, e sim como um público complexo e heterogêneo:

No caso das crianças, suas relações com a mídia são estruturadas e restringidas por discursos e instituições sociais mais amplos, que (entre outras coisas) procuram definir a infância de formas particulares. O público infantil - ou, pelo menos, as características específicas desse público - é, então, construído por meio de um processo contínuo de negociação social (Buckingham, 2012, pp. 114).

O trabalho de Tomaz (2017) está em sintonia com o que diz o autor. A pesquisadora investigou como crianças comuns, ao utilizarem sites de redes sociais, especialmente o YouTube, produzem lugares de relevo social e, assim, afetam a construção social da infância. Ao analisar canais de youtubers mirins e ao conversar com os espectadores, Tomaz aponta tais canais como um exercício 
de participação social das crianças. A autora reflete que as crianças assumem a posição de sujeitos de processos comunicacionais, produzem narrativas da infância, atuando, assim, na construção dessa categoria. Tomaz (2017, pp. 1) constata "que os usos das crianças na plataforma de vídeos permitem que elas produzam novas sociabilidades às quais também se submetem. Tais interações apontam para o surgimento do que se pode chamar de uma cultura lúdica infantil digital.". É necessário, portanto, perceber o que as crianças estão dinamizando nas redes.

Nesta pesquisa, tenho visto, por exemplo, a incorporação intensa de cosméticos e de práticas de embelezamento nos cotidianos de crianças pertencentes a diferentes realidades econômicas e culturais, o que certamente alimenta o desempenho do mercado da beleza. As linhas de produtos de beleza exclusivos para crianças cresceram mais de $40 \%$ em dois anos (Abiphec, 2015). Se, por um lado, a presença dos cosméticos e do engajamento para construir um corpo belo nas vidas de meninas e meninos pode corroborar práticas saudáveis pertinentes ao cuidado de si, às noções de higiene, ao zelo corporal e à autoestima, por outro, a partir do momento que assumem uma face excessiva, podem prejudicar seriamente as crianças tanto na dimensão psicológica quanto física, tornando-se um problema de saúde pública. O uso incorreto de cosméticos, por exemplo, pode desencadear reação alérgica (Vírgula, 2010). Já os constantes alisamentos e colorações do cabelo podem provocar irritações no couro cabeludo (Portal G1, 2009).

Ciente do uso intensivo de cosméticos pelas crianças, a Anvisa ${ }^{19}$ determinou normas para a adequação do comércio desses tipos de produtos. Assim, foi estabelecida a faixa etária para o público infantil, que vai de 0 a 12 anos, para o uso de cada categoria de cosmético. O esmalte para unhas, por exemplo, só pode ser utilizado por crianças a partir de 5 anos. Crianças com 3 anos podem usar sombra e batom com a ajuda de um adulto. Depois dos 5 anos, elas mesmas já podem utilizar os produtos sozinhas. Essas medidas adotadas pela instituição são mais um indício da presença cotidiana de cosméticos e práticas de embelezamento nas vidas das crianças.

É importante frisar, nesse sentido, que a intenção aqui não é culpabilizar os familiares e os salões de beleza, tampouco os vídeos do YouTube pelos usos excessivos de cosméticos ou serviços estéticos pelas crianças nem pelas relações que estas estabelecem com seus corpos. Antes disso, procuro refletir sobre os sentidos do contexto social que orientam ou impõem exigências em torno da beleza que podem gerar discriminação de corporalidades infantis e prejuízos à saúde física e emocional de meninas e meninos.

Para darmos continuidade a essa discussão, menciono o caso emblemático da boneca Momo, que repercutiu com força recentemente nas redes sociais, tornando-se fonte de profunda preocupação de pais e familiares quanto à utilização da internet pelas crianças. Momo, com sua aparência assustadora, faz aparições em meio a vídeos infantis no YouTube, transmitindo mensagens de estímulo ao suicídio. A boneca instrui os modos de cometê-lo e os equipamentos para o intento, os quais podem ser encontrados com relativa facilidade em casa. Em todas as paragens da presente pesquisa, Momo foi alvo de espanto, indignação e discussão. Ouvi frases de familiares como: "Vou proibir minha filha de assistir youtuber! " ; "Não poderia imaginar uma loucura dessas. Eu já tomei o tablet"; "Eu pensei que o meu filho estivesse seguro em casa, mas não! Um horror".
19. Ver resolução $\mathrm{RDC}$ № 15 , de 24 de abril de 2015, estabelecida pela Anvisa, que estipula requisitos para o uso de cosmético infantis no Brasil. Disponível em: http:// pesquisa.in.gov.br/imprensa/jsp/ visualiza/index.jsp?jornal=1\&pagin $a=47 \&$ data $=27 / 04 / 2015$. Acesso em: 8 de maio de 2017 . 
Diante dessas falas, refleti sobre tantos vídeos sobre embelezamento que diariamente são vistos pelas crianças e que, por vezes, podem ser prejudiciais à saúde física e emocional. Por exemplo, aqueles que apregoam um consumo desenfreado, o uso intensivo de cosméticos, muitos com substâncias inapropriadas para a pele das crianças. No entanto, não há preocupação tão evidente dos familiares com esses conteúdos. Outro dado que esse caso denota é que o espanto evidenciado nas falas mostra um distanciamento dos diálogos mais sistemáticos sobre a utilização das redes entre crianças e responsáveis.

Sobre o modo como as crianças manejam as categorias corpo e beleza, operacionalizadas nos vídeos e nos salões, afirmo que algumas reiteram parâmetros de beleza e critérios normativos de distinção de gênero, como, por exemplo, uma menina de 5 anos que se recusa a ficar de mãos abertas se suas unhas não estiverem devidamente esmaltadas. Outra menina, de 7 anos, perguntou se havia alguma cirurgia capaz de afilar seu nariz e assiste a tutoriais de maquiagem com tal intento. Vi uma garota de 12 anos que negocia notas boas na escola em troca de poder assistir a tutorias de beleza no YouTube e de ganhar os produtos neles anunciados; observei ainda um menino que voltava constantemente ao salão de beleza para atualizar o cabelo, conforme o corte e o colorido de seu youtuber preferido.

Em contrapartida, também registrei cenas de crianças negociando, deslocando e negando tais padrões de beleza e as noções rígidas de diferenciação de gênero. É o caso de uma menina de 10 anos que se recusou a manter seus cabelos compridos, mesmo diante dos apelos da mãe. Uma outra, de 11 anos, recusou-se a tirar as sobrancelhas e não gosta de se submeter à rotina dos salões, embora seja estimulada a isso por seus familiares. Presenciei meninas que queriam cabelos curtos e meninos que desejavam manter suas madeixas grandes. Um garoto, com 6 anos, acompanha os tutoriais de maquiagem. Pude conviver com meninas que apreciam assistir a vídeos sobre viagens e games e não gostam dos tutoriais de beleza.

Vale mencionar, diante dessas cenas, que as negociações entre pais/responsáveis e crianças são complexas e diferenciadas: às vezes, permeadas de conselhos; em outras, de choros, constrangimento ou risos. Tais cenas evidenciam ainda que o corpo que se tenta educar ou disciplinar nunca é uma massa inerte, "desinformada" ou, a priori, passiva (Sant'Anna, 2000). Assim, não podemos dizer, com efeito, que todas as crianças reagem de forma acrítica diante dos discursos e estímulos presentes nos salões e nos vídeos pautados, nem que existe, entre elas, uma interpretação homogênea acerca desses apelos. Como defende Louro (2016), os atores infantis não são meros receptores passivos de processos pedagógicos externos, mas sim agentes que participam ativamente desse empreendimento.

Apesar dos estímulos presentes nos vídeos e nos salões não indicarem necessariamente uma domesticação corporal, eles se mostram fortes nos cotidianos de algumas crianças no sentido de orientarem e incentivarem normatizações de corpo, beleza e gênero. Ao frequentarem os salões e assistirem aos vídeos, as crianças convivem com práticas e valores anunciados em torno da beleza física e das formas de ser. Elas vão manejando e negociando, reiterando ou desestabilizando esses aprendizados, ou seja, convivendo de alguma forma com eles em suas trajetórias.

Pela análise das narrativas, depoimentos e cenas, percebi que, para muitas crianças, as experiências vividas nos salões e apreendidas nos vídeos não se 
encerram no momento em que essas crianças saem desses estabelecimentos ou desligam seus aparelhos eletrônicos. Em muitos casos, tais experiências permanecem ressoando, refletindo-se nos modos como as crianças percebem suas próprias imagens corporais e as de seus pares. Não podemos atribuir aos salões ou aos vídeos o pleno poder de definir as identidades sociais, mas afirmo que eles possuem um efeito pedagógico e que podem constituir parte significativa nas relações que as crianças estabelecem com seus corpos.

A pesquisa apontou que na relação das crianças com os vídeos apresentados, elas não apenas lidam, cotidianamente, com a reiteração da estética branca, magra, de cabelo liso e loiro, nutrida, com vigor, por espaços de embelezamento, indústria estética e cosmética, meios de comunicação de massa. Elas lidam, de forma sistemática, com as diretrizes para esquadrinhar seus corpos de modo a se aproximar, ainda que minimamente, do referenciado padrão. A citação acentuada dessa imagem corporal indica muito mais que a valorização de uma concepção de corpo belo; a citação normatiza e cria uma inteligibilidade em torno das formas físicas que são dignas de representatividade. Ocorre, como diria Butler um processo de reforço e permanência do sentido. As imagens veiculadas nos vídeos apresentados "determinam o que será inteligivelmente humano e o que não, o que se considerará real e o que não, estabelecem o campo ontológico no qual se pode atribuir aos corpos expressão legítima" (Butler, 2007, pp. 29).

Face a isso, é fundamental debater, entre outras coisas, o consumo ali incitado e os prejuízos ao bem-estar físico, social, emocional que isso tem gerado nas vidas de crianças de diferentes classes sociais, raças, gêneros, idades. Todavia, pensemos também como nem a relação com a internet nem a com o consumo são algo que possa ser definido a priori, pois estão em construção e podem ser pensadas para o reconhecimento e a valorização de diferentes formas físicas e modos viver.

Nesse sentido, aludo a Haraway (1994), quando mostra como, desde a mais tenra idade, as tecnologias estão presentes de forma incisiva nos cotidianos dos mais diversos sujeitos sociais, e às vezes presentes de forma completamente assimétrica, sobretudo no que tange à classe. A pesquisadora nos desafia justamente a esse movimento: pensar as tecnologias de maneira mais democrática. Assim, é possível pensar os usos da internet e o consumo que esses usos envolvem de modo a não auxiliar na produção e propagação de padrões estreitos de beleza e a promover formas mais democráticas de perceber a beleza física. Um relatório publicado pelo Fundo das Nações Unidas para a Infância (UNICEF) revelou que a cada segundo duas crianças entram na internet pela primeira vez. ${ }^{20}$ Enfrentar o debate sobre o direito delas tanto ao acesso como aos usos seguros e saudáveis dessa tecnologia torna-se, portanto, um imperativo que deve ser enfrentado coletivamente.

\section{Considerações finais}

Como salienta Sant'Anna (2000, pp. 237), “O conhecimento do corpo é por excelência histórico, relacionado aos receios e sonhos de cada época e grupo social." Hoje em dia, tal conhecimento está massivamente difundido na internet. Não é proibindo as crianças de acessar as tecnologias que uma forma democrática de pensar a educação das corporeidades se concretizará. Isso ocorrerá, antes, por meio da construção social de estratégias saudáveis para esse acesso. Pensar coletivamente, como um assunto de saúde pública, pautas
20. Disponíel em: https:// nacoesunidas.org/a-cadasegundo-2-criancas-entram-nainternet-pela-1a-vez-diz-unicef/ Acesso em 1 de Outubro, 2019. 
como a regulamentação para publicidade infantil no YouTube, é algo urgente. É preciso discutir também sobre essa frágil ideia de infância protegida por "estar dentro de casa e diante de uma tela". Na esteira dos estudos da infância (Cohn, 2005; Corsaro 2011; Sarmento, 2003), acredito que uma chave para esse intento seja a escuta atenta das crianças, percebendo-as como sujeitos ativos nesses processos comunicacionais. Relações dialógicas entre adultos e crianças sobre os conteúdos audiovisuais podem dinamizar formas mais saudáveis e democráticas de pensar o uso das redes. No caso do embelezamento, tal uso pode ser um aliado para questionar padrões rígidos de beleza que, por vezes, instauram nas pessoas, das mais diferentes idades, um sentimento de insuficiência, culpabilidade e vergonha, e evidenciam mecanismos de reprodução de desigualdades.

\section{Sobre la autora}

Doutoranda em Ciências Sociais da Universidade Estadual de Campinas, na linha de gênero. Mestre em Sociologia e bacharel em Ciências Sociais pela Universidade Federal do Ceará. 


\section{Q Referências bibliográficas}

"Arango, L. (2016). Cuidado, emoções e condições de trabalho nos serviços estéticos do Brasil. Em A. R. Abreu, H. Hirata e M. R. Lombardi (Orgs.). Gênero e trabalho no Brasil e na França (pp.223-32). São Paulo: Boitempo.

» Bouzón, P. (2010). Construindo identidades: um estudo etnográfico sobre manipulação da aparência em salões de beleza. (tese de doutorado), Universidade Federal do Rio de Janeiro, Rio de Janeiro, Brasil.

"Butler, J. (2002). Cuerpos que importan: sobre los límites materiales y discursivos del "sexo". Buenos Aires: Paidós.

》Butler, J. (2007). El género en disputa. El feminismo y la subversión de la identidad. Barcelona: Paidós.

" Buckingham, D. (2012). As crianças e a mídia: uma abordagem sob a ótica dos estudos culturais. Matrizes, 5(2), 93-121.

"Brah, A. (2006). Diferença, diversidade, diferenciação. Cadernos Pagu, 26, 329-76.

" Cohn, C. (2005). Antropologia da Criança. Rio de Janeiro: Jorge Zahar.

"Corsaro, W. A. (2011). Sociologia da infância. Porto Alegre: Artmed.

»Delgado, A. C. C. e Muller, F. (2005). Apresentação. Sociologia da Infância: pesquisa com crianças. Educação e Sociedade, 26 (91), 351-60.

》Dornelles, L. V. (2005). Infâncias que nos escapam: da criança na rua à criança cyber. Petrópolis: Vozes.

"Edmonds, A. (2002). No universo da beleza: notas de campo sobre cirurgia plástica. Em M. Goldemberg (Org.). Nu e vestido (pp. 189-261). Rio de Janeiro: Record.

》Fanon, F. (2008). Pele negra, máscaras brancas. Bahia: Edufba.

"Finco, D. e Oliveira, F. (2011). A sociologia da pequena infância e a diversidade de gênero e de raça nas instituições de educação infantil. Em A. L. Goulart e D. Finco (Orgs.). Sociologia da infância no Brasil (pp. 55-80). Campinas: Autores Associados.

» Gomes, N. L. (2008). Sem perder a raiz: corpo e cabelo como símbolos da identidade negra. Belo Horizonte: Autêntica.

" Gomes, N. (2002). Corpo e cabelo como ícones de construção da beleza e da identidade negra nos salões étnicos de Belo Horizonte. (tese de doutorado), Universidade de São Paulo, São Paulo, Brasil.

" Gerasimczuk, L. C. e Karageorgiadis, E. (2017). Publicidade dirigida à criança na rede: ilegalidades nos canais de youtubers mirins. Em Comitê Gestor da Internet no Brasil (Ed.). TIC Kids Online Brasil: pesquisa sobre o uso da internet por crianças e adolescentes no Brasil (pp. 39-46). CGl: São Paulo.

" Geertz, C. (1989). Uma descrição densa: por uma teoria interpretativa da cultura. Em A interpretação das culturas (pp. 13-41). Rio de Janeiro: LCT.

» Girardello, G. (2008). Produção cultural infantil diante da tela: da TV à Internet. Em M. Fantin e G. Girardello (Orgs.). Liga, roda, clica: estudos em mídia, cultura e infância (pp. 127-44). Campinas: Papirus.

» Hamann, F. (2002). Erotização da Infância e Meios de Comunicação de Massa. Rio de Janeiro: UFRJ. 
" Haraway, D. (1994). Um manifesto para os cyborgs: ciência, tecnologia e feminismo socialista na década de 8o. Em Tendências e impasses: o feminismo como crítica da cultura (pp. 243-88). Rio de Janeiro: Rocco.

"Louro, G. (2016). O corpo educado: pedagogias da sexualidade. Belo Horizonte: Autêntica.

» Muller, F. e Hassen, M. (2009). A infância pesquisada. Revista de Psicologia da USP, 20(3), 465-8o.

»Peirano, M. (2014). Etnografia não é método. Horizontes Antropológicos, 20(42), 225-70.

» Ponte, V.P. (2018). Beleza, produção e normalização do corpo em narrativas de crianças. Civitas, 18, 153-170.

"Sampaio, I. (2000). Televisão, publicidade e infância. São Paulo: Annablume.

»Sant'anna, D. (200o). As infinitas descobertas do corpo. Cadernos Pagu, 14, 235-49.

»Sarmento, M. (2003). Imaginário e culturas da infância. Cadernos de Educação, 12(21), 51-69.

» Sirota, R. (2011). Emergência de uma sociologia da infância: evolução do objeto e do olhar. Cadernos de Pesquisa, 112, 7-31.

»Sousa, E. (2017). Corpo, pessoa e identidade Capuxu através da infância. Florianópolis: UFSC.

» Tomaz, R. (2017). Youtubers mirins: como a produção de conteúdo on-line por crianças sinaliza uma cultura lúdica digital. Congresso da Associação Nacional de Pós-graduação e Pesquisa em Ciência Sociais (Anpocs). Disponível em: https://www.anpocs.com/index.php/papers-40-encontro-2/gt-30/gto2-25/10607-youtubers-mirins-como-a-producao-de-conteudo-on-line-por-criancas-sinaliza-uma-cultura-ludica-digital/file.

\section{Outras fontes consultadas}

»Vírgula (2010). Dermatologista alerta para os riscos da maquiagem em crianças. Disponível em:http://www.virgula.com.br/home/legado/dermatologista-alerta-para-osriscos-da-maquiagem-em-criancas/.

»Portal $\mathrm{G}_{1}$ (2009). Especialistas alertam para riscos do alisamento de cabelo em crianças. Disponível em: http://g1.globo.com/Noticias/Brasil/o,,MUL971210-5598,oo. 